\title{
Equity-Oriented Pedagogical Strategies and Student Learning in After School Making
}

\author{
Jean J. Ryoo \\ Exploratorium \\ Pier 15 \\ San Francisco, CA 94111 \\ 011-415-528-4404 \\ jryoo@exploratorium.edu
}

\author{
Lianna Kali \\ Exploratorium \\ Pier 15 \\ San Francisco, CA 94111 \\ 011-415-528-4665 \\ Ikali@exploratorium.edu
}

\author{
Bronwyn Bevan \\ University of Washington \\ Miller Hall, College of Education \\ Seattle, WA 98195 \\ bronwynb@uw.edu
}

\begin{abstract}
The maker movement holds great promise to improve the educational experiences of all learners, regardless of age, race/ethnicity, gender, home language, ability, or socioeconomic class. This paper describes how we sought to fulfill this promise by creating a new after school making program serving working class and low-income youth of color in East Oakland. Building on our prior efforts investigating equity-oriented tinkering in after school settings $[1,2]$, the work described here is part of a larger study led by the Research + Practice Collaboratory (see www.researchandpractice.org). The Collaboratory formed a partnership with the Lighthouse Community Charter School of East Oakland to examine how afterschool tinkering programs support the development of student learning outcomes that are valued during the school day, specifically the development of learning dispositions, creative problem solving, and deeper understanding of STEM concepts and practices. After describing pedagogical strategies (in program/curriculum design and teaching moves) our program used to build a creative making culture, we share a detailed case describing what learning outcomes looked like for a Latina $5^{\text {th }}$ grader (Katrina) who had never been in a making program, never worked with circuitry or soldering, and did not initially identify as a "maker."
\end{abstract}

\section{CCS Concepts}

- Social and professional topics $\rightarrow$ Computational thinking.

\section{Keywords}

Making, Tinkering, Equity, Expansive Learning, Pedagogy, Curriculum and Activity Design, Research-Practice Partnership, After School Education.

\section{INTRODUCTION}

\subsection{Today's Making Landscape}

There is growing research literature documenting the many ways that making programs support deep student engagement and

Permission to make digital or hard copies of all or part of this work for personal or classroom use is granted without fee provided that copies are not made or distributed for profit or commercial advantage and that copies bear this notice and the full citation on the first page. Copyrights for components of this work owned by others than the author(s) must be honored. Abstracting with credit is permitted. To copy otherwise, or republish, to post on servers or to redistribute to lists, requires prior specific permission and/or a fee. Request permissions from Permissions@acm.org.

FabLearn '16, October 14 - 16, 2016, Stanford, CA, USA

Copyright is held by the owner/author(s). Publication rights licensed to

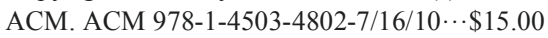

DOI: http://dx.doi.org/10.1145/3003397.3003404 learning $[3,4,5]$. This research suggests that making is engaging, because it builds on personal interests rather than external demands to find answers to inquiries [6]; making provides opportunities for multidisciplinary engagement for a wide range of purposes that can legitimize non-school based practices for youth who may feel out of place in school [7, 8]; making allows access to powerful ideas, tools, and literacies that were previously only accessible to professionals [9, 10]; and making, bringing together communities of makers, can support STEM identity development $[11,12]$.

However, there are legitimate questions about how making programs and makerspaces can be designed or implemented in ways that support equity in education. From Buechley's [13] analysis of the US maker movement's primarily white, middle class, male focus to Chachra's [14] critique of the maker movement's prioritization of creating marketable products over celebrating the caregiving interactions that occur between educators and learners, there is concern that making is something for only the most privileged while offering definitions of knowledge and learning that are too narrow. Building on a critique of the "sameness as fairness" approach to providing access to making for all youth [15], Vossoughi, Hooper, and Escudé [16] caution makerspaces to not reproduce the inequitable educational experiences that many working class youth of color have had as "targets of intervention rather than sources of deep knowledge and skill [wherein] dominant communities are reinscribed as being ahead, with something to teach or offer rather than something to learn" (p. 212).

\subsection{Purpose and Goals}

These critiques of making are important calls to action. This paper attempts to continue the conversation in positive directions by sharing descriptions of how equity-oriented pedagogical strategies (through program/curriculum design, professional development, and teaching practice) were leveraged to support students across an array of making experiences. We share detailed descriptions of one such student's trajectory (we have given her the pseudonym "Katrina") as her participation and learning deepened over a single semester. The paper examines the following questions:

1) What pedagogical strategies, professional development, and pedagogical moves foster a program culture that supports students to take the creative and intellectual risks entailed in making while deepening their skills and learning over time?

2) What does the deepening of student participation, interest and learning look like within such a program culture?

As several scholars have noted, to date there has been little attention paid to the pedagogy of making [5, 17]. The data, presented here through a description of our afterschool program's 
design as well as in the form of one student's case, were collected as part of a larger study, led by the Research + Practice Collaboratory. This study involves a research-practice partnership between the University of Washington, Exploratorium of San Francisco, and the Lighthouse Community Charter School of East Oakland.

We will begin by describing the context of our work and the afterschool program followed by research methods used in our partnership. Next, we share strategies undertaken to support (1) developing a partnership with professional development for after school educators that rooted the making program in local knowledge and interests, (2) program and curriculum design focused on building a creative maker culture in an afterschool program serving youth from low-income communities, and (3) the facilitation of student learning trajectories within this culture. Then, we will provide a case study describing the learning trajectory of a Latina $5^{\text {th }}$ grader (Katrina) who had never attended a making program before, never worked with circuitry or soldering, and did not initially identify as a "maker." Finally, we will discuss the importance of these findings in the larger context of educational research and making.

This paper addresses a need in the current literature: few articles describe in qualitative detail the important ways that educator professional development, equity-oriented pedagogical moves, and student learning intersect in making contexts. By tying together how these three areas relate to one another in our after school making program, we hope to show the important relationships among these three tiers of educator learning, educator practice, and student learning.

\section{CONTEXT OF STUDY AND METHODS}

Our work over the past several years has sought to build on almost two decades of design and research on making as a powerful context for learning, primarily in museums $[18,19]$. In 2012, we began investigating the ways in which maker activities developed in the Exploratorium Tinkering Studio could be productively adapted into afterschool programs serving low-income communities $[1,20]$. This work has emphasized the need for professional development that can help educators serving youth from racially and economically marginalized communities to fully leverage their students' interests and funds of knowledge, while at the same time fostering creative communities of practice in which young people can take the kinds of creative and intellectual risks that making requires but that under-resourced schools often discourage and even punish.

The Exploratorium focuses on tinkering as a branch of making that emphasizes a "playful, experimental, iterative style of engagement, in which makers are continually reassessing their goals, exploring new paths, and imagining new possibilities" [21, p. 164]. Grounded in constructionist pedagogies [22], the Exploratorium Tinkering Studio's approach to learning design is blended, in the afterschool context, with cultural-historical approaches to learning as a process of being, doing, knowing, and becoming $[19,23]$. Thus afterschool making programs and activities are designed to leverage and expand students' funds of knowledge through ensuring that programs are meaningful, culturally responsive, and connected to ideas, activities, or settings in the broader community [24].

The Lighthouse Community Charter School, where this study takes place, is a K-12 school serving 750 students. $85 \%$ are from low-income families, $80 \%$ are English Language Leaners, 90\% will be the first in their families to go to college. Ethnically,
Lighthouse students are 79\% Latino, 12\% African American, 3\% Asian, and $6 \%$ are white or multiracial. Lighthouse offers on-site afterschool programs for over 100 youth daily.

Over 12 weeks during the spring of 2016, educators from the Tinkering Studio and Lighthouse co-taught a weekly afterschool making program. Researchers from the Exploratorium and University of Washington attended the program each week, documenting student activities and helping facilitators and youth as needed. Using participant observation methods, researchers documented everyday experiences of learning and teaching to identify the meaning that those experiences had for those who participated in them [25]. Data sources included observation field notes, videos, photos, student work, audio recordings of postprogram reflections between educators and researchers, interviews with teachers, and interviews with students.

Once a month, the research-practice partnership met to review program data together, reflecting on program design, pedagogy, and student learning through research data analysis as a form of professional development for after school educators. These collaborative reflections and observations about the data were used to develop a data-coding scheme, triangulated with the research, that have informed this paper and will be further developed as we begin to trace learning into the school day.

Lianna Kali was the lead educator from the Tinkering Studio who worked closely with Lighthouse educators to run the after school making program. Jean Ryoo was the researcher collecting data during the after school program. Bronwyn Bevan was the PI of this study, working with Lighthouse staff to lead monthly research practice partnership meetings. Blogs about Lianna and Jean's collective learning process through research can be found on the Research + Practice Collaboratory blogsite (http://researchandpractice.org/learning-through-partnershipafterschoool/).

\section{PEDAGOGICAL STRATEGIES OF EQUITY-ORIENTED MAKING}

\subsection{Building a Partnership and Professional Development Model Focused on Local Knowledge and Interests}

\subsubsection{Designing the Program According to Local Knowledge and Interests}

Before implementing this program, museum educators, activity developers, researchers, Lighthouse after school teachers, and leaders met several times to co-develop a curricular plan for the months ahead. While this was important for building positive communication norms between key stakeholders in the project, this was also important for gaining a better understanding of Lighthouse students' and staff's educational context.

During the first meeting, Exploratorium activity developers and educators arrived with a range of potential curricular ideas that could be explored during the semester with the goal of receiving input from school staff about what they knew youth would be curious about or interested in before curricular decisions were made. This conversation resulted in important local insight into the types of activities and scientific experimentation that the students already knew or wanted to know more about, specifically related to circuitry and circuit bending. School staff informed Exploratorium activity designers about their students' experiences and needs. We collectively agreed that it would be important to 
offer new and interesting activities related to the known interests that youth already had within the school community rather than bring activities in from the "outside" that were unrelated to local knowledge.

During the second meeting, the entire research-practice partnership spent time getting to know one another better, experiencing a tinkering activity together, and then developing a shared understanding and language around peoples' values in relation to after school making. In a value mapping exercise [26] that was intended to surface similarities and tensions across peoples' ideas, values, and vocabulary in joint work, partners reflected on what they valued about: 1) the youth they work with; 2) making education; and 3) after school spaces. This initial reflection served as a valuable starting point for framing the after school making program by highlighting the positive resources that educators believed Lighthouse youth brought to the table, the possibilities of making activities, and the importance of an informal education space.

The meetings described above launched a series of monthly professional developments in which after school educators, Exploratorium staff, and researchers continued to make sense of student learning through making, pedagogical moves important to equity-oriented learning, and how experiences in after school could relate to the school day. Together we read fieldnote excerpts and looked at videos of students making. We discussed what we noticed about learning and teaching as well as questions these data sources brought up for us.

These meetings fostered a space where educators could identify and discuss pedagogical moves that supported equity-oriented learning that produced the development of student learning outcomes valued during the school day (results of which are forthcoming). For example, in these meetings Lianna would share personal reflections on her teaching practices and the student learning she observed with Lighthouse colleagues. This, in turn, supported teachers to return to their programs with renewed interest in paying attention to details of teaching and learning that they then shared within our learning community in the weeks that followed. Educators from both the Exploratorium and Lighthouse used this professional development time to reflect on how the sessions impacted their practice and understanding of student learning. These professional development opportunities were an important part of teacher learning and another key pedagogical strategy to equity-oriented making that we recognized in our work together.

Using feedback from these meetings and professional development workshops, the Exploratorium Tinkering Studio team developed a set of activities to meet the local perspectives, learning interests, and needs of Lighthouse. These activitiesboth previously implemented and newly created for piloting with youth-were also rooted in Tinkering Studio design principles regarding activity design, environmental design, and facilitation strategies $[19,27]$ while building off previously documented features of equity-oriented teaching [20].

More specifically, to support a culture of creative and intellectual risk-taking, we built on prior work to ensure that program activities were designed, sequenced, and positioned in ways that created opportunities for all youth, whatever their prior experiences, to fully participate in the activities. Features we attended to included selecting activities with multiple entry-points and pathways, activities and sequencing of activities that supported students to "level-up" or complexify their work [19], and activities that built relationships and understanding among youth and adults.

\subsection{Curriculum Design Fostering a Supportive Culture for Creative Risk-Taking}

\subsubsection{Multiple Starting Points and Pathways: Low Floors, High Ceilings, and Wide Walls}

Recognizing that not all students would be arriving with knowledge of circuitry or making nor feel comfortable with STEM concepts or practices, attention was paid to starting off the semester with an activity that required no previous knowledge or skills yet involved familiar materials and objects. This activity, called "Toy Take-Apart" (details about this activity are available at: http://tinkering.exploratorium.edu/toy-take-apart), involved giving students old battery-operated toys that they could dissect in order to learn about how internal circuitry powered movement or sound. Students were given a range of tools that were both familiar and new (from screwdrivers to multimeters) that they could use to explore the inner workings of recognizable Donald Duck or Valentine's plush toys. They took notes in their journals as they learned about the circuitry inside the toys. By the end of the first couple of meetings, students had pulled out circuitry parts that they wanted to repurpose in the next week's activity which involved creating homemade circuit boards that would be donated to a school-day making class.

This approach to the semester's first making activities was important to ensuring that both experienced and inexperienced youth (and those who identify or don't identify as "makers") could feel comfortable exploring circuitry in making. In past iterations of this activity, we have seen how children can find it off-putting to take apart a working mechanical toy because it may feel wasteful to "destroy" what is already functional. However, within this after school program context, providing toys that were used and familiar to youth that could be hacked for a new and meaningful school purpose-donating circuit boards that younger students could use to learn about circuitry - grounded the activity in a larger community-oriented purpose beyond dissection for dissection's sake.

\subsubsection{Learner-Directed Leveling Up}

Another key strategy to supporting a culture of creative risktaking involved providing students opportunities to build on previous activities and projects over time toward deeper learning and complexification of ideas and skills throughout the semester.

Lianna was used to facilitating one-off making activities with museum visitors of the Tinkering Studio. As a result, she had rarely explored opportunities to have one making activity inform the next nor watch individual learners grow with their ideas over time. She was excited to develop a curriculum that carefully built on activities over time so that youth could go deeper with their ideas while developing or honing new skills.

As will be illustrated in the student case below, this attention to building on activities in the curriculum over time was an important way to support students in complexifying their ideas and gaining confidence in their skills throughout the semester. This was especially important for youth who came into the program with little to no experience with making programs or circuitry. While it may seem obvious that learning in making spaces is best supported by building on activities/skills over time, this is actually an uncommon practice across many making spaces where activities may not relate to one another directly or where 
drop-in students may pursue individual projects that do not connect across other activities.

Finally, when developing the curriculum, special attention was paid to creating space for youth perspectives, initiative, and personalization of projects. While projects had general goals (e.g., create a greeting card or personalized paper art that incorporates circuitry with batteries, copper tape, and LEDs), activities were carefully designed so that youth could set their own goals, develop unique problem-solving strategies based on their needs, and have self-driven intentionality to their projects. In practice, this meant that although students were all working in a similar problem-space, no two students' projects looked the same. Each artifact then served as evidence of individual pathways and problem solving through various making processes.

\subsubsection{Activities to Build Relationships}

A final key feature of the after school making program that we found essential to youth engagement/learning involved building $a$ community of learners where adults and youth could get to know each other's personalities, interests, and perspectives on a friendly, human level. This occurred both formally and informally.

Formal methods of building community-important in a space that included middle school students who belonged to different grades and social cliques - included regularly starting every program meeting with an opening conversation. Sharing in the conversation was optional, but listening was not. While short and simple, these opportunities for youth to describe a personal experience related to past creative projects, to come up with a sentence in a collective story-telling activity, or to share what they noticed while working on a circuitry project the previous week helped youth and adults to get to know one another while also grounding the rest of the program in a more personal tone.

Another important formal method was making a concerted effort to connect youth to artists of color from the community. Through both a field trip to an artist's studio in his home garage to a program visit from an artist who works with sewn circuitry, specific effort was made to see how making connected to life outside the after school program and could be pursued by people who looked like Lighthouse youth. The ways youth made these connections to themselves became visible when Allison (Latina $8^{\text {th }}$ grader) asked an artist about whether his art project could be on the sidewalk in her neighborhood too.

Informal methods involved adults talking with youth about popular culture (sharing music, discussing favorite animé, etc.) and adults talking with both fellow adults and youth with the same tone of voice and comfort-level modeling the type of interactions valued in the space (for example, adults asking questions about each other's making projects in front of youth, or sharing different methods of threading a needle with each other and youth).

\subsection{Expansive and Equity-Oriented Pedagogical Moves to Spark and Sustain Student Participation}

In addition to documenting how program and curriculum design focused on fostering a creative culture, we documented the specific kinds of pedagogical moves that facilitators made to spark and sustain student' creative making and problem solving.

\subsubsection{Asking Questions}

A common teaching practice observed in the program included asking questions that did not assume what youth did or didn't know while finding ways to connect to what youth demonstrated they understood or previously experienced.

For example, when introducing a new tool, Lianna would ask "does this look familiar to you?" This simple question could elicit a range of responses from "yes, I've seen that before during..." to "yes, it reminds me of..." to "no, what is it?" Based on students" responses to this question, Lianna would then give youth opportunities to demonstrate their skills if the tool was known to them, scaffold new tool use with familiar tools by using metaphors that related new ideas to what the student mentioned knowing, or explain step-by-step what the tool was used for and why while leaving room for questions and curiosity.

Furthermore, Lianna wouldn't simply try to get through teaching new tool-use as if it was a chore toward a more important goal of making, but rather she would use these moments as opportunities for youth to draw their own connections and explorations from new skills. For example, when teaching Antero (a $7^{\text {th }}$ grade Latino student) how to use a multimeter tool to check his circuit's conductivity, Antero decided to use the tool to check the electricity flow of a battery as well. Rather than try to refocus his newly learned tool use toward the copper tape circuit in his project, Lianna gave Antero the space to tinker with the multimeter tool and battery and make observations in relation to what he already knew about batteries. He talked about the positive and negative charges of the battery and asked questions about what the tool's beeping sound suggested regarding conductivity of the battery itself. In this way, every time educators taught a skill they were familiar with, youth were given an opportunity to make the experience their own or different based on the knowledge and questions they brought to the table.

\subsubsection{Supporting Self-Directed Learning}

Self-directed learning does not mean teacher-less learning. Rather it means teaching in ways that support learners to identify, develop, and pursue their ideas and interests. As such, educators were careful never to take over students' projects while giving them room to do things in their own way. This approach highlights the pedagogical approach to equity-oriented practice that "widen[s] definitions of learning, intelligence and science" [20].

For example, when Katrina was testing her second paper circuit to figure out why her LED wasn't lighting up, she noticed that the LED would light up when she pressed the tip of her multimeter tool against the leg of the LED. Lianna thought that the multimeter tool must be sending electricity to the LED, causing it to light up. However, Katrina believed that the LED wasn't connected well enough and needed more weight pushing down on it to properly light. Rather than challenge this idea, Lianna stepped back, allowing Katrina the room to try out her hypothesis about added pressure to the LED. Katrina proceeded to press down another layer of scotch tape on top of the LED, adding extra pressure on the connection to the copper tape circuit. This worked, reemphasizing for Lianna how important it was to not intervene in that moment and why youth should be given the opportunity to try doing things their own way.

\subsubsection{Supporting Peer-to-Peer Learning}

Developing an expansive and equity-oriented making space also required attention to creating a welcoming and social learning environment where youth can learn together and from one another. So, for example, when Ryan (Tinkering Studio educator) reviewed how to solder with Katrina, he welcomed Antero to watch the process and touch the materials so he could learn from 
Katrina's work. This ignited a deep and new interest in soldering for Antero in subsequent projects.

Furthermore, pedagogical moves that modeled valuable forms of assistance that taught youth how they could help each other included offering to be "extra hands" at key moments without taking over a project. For example, soldering down the legs of a gum-drop LED was done best when one hand held tweezers to hold down the leg, a second hand held the solder, and a third hand held the soldering iron. This type of assistance was also visible among students; when one student wanted to sew a plush heart to a metal bracket to create a circuit board, her friend held the heart and bracket in place while she did the sewing.

\section{Case Study: Katrina's Learning Trajectory}

We highlighted the above pedagogical strategies (program/ curriculum design and pedagogical moves) of our making program to emphasize that youth learning in makerspaces does not happen independent of teaching and sociocultural interaction [16]. In fact, we believe that activity/curriculum design, attention to the sociohistorical and cultural contexts of youth and their communities, as well as expansive and equity-oriented pedagogical moves are key to supporting student learning.

While the learning trajectories of the youth in our after school making program varied, with projects taking a range of different directions and students taking on diverse challenges and problems, we saw almost all the students' ideas and creative problem solving skills growing and shifting in important ways.

In the following vignette, we share how the pedagogical decisions involved in fostering an afterschool culture of creative risk-taking are leveraged to support student learning trajectories. In particular we highlight how these teaching decisions have led to learning outcomes related to the development of learning dispositions, capacities for creative problem solving, and STEM understanding.

\subsection{Katrina's Projects - Increasing Complexity Over Time}

Katrina's projects over the course of the semester evidenced deepening fluency with circuitry-related skills and concepts, creative problem solving, and a range of learning dispositions and skills, such as self-direction and persistence.

\subsubsection{Katrina's First Paper Circuit}

Near the start of the semester, students created paper circuits. Paper circuits use copper tape and surface-mount LEDs to make a fully functional circuit on flat paper surfaces. Students can make light-up greeting cards, origami animals, or 3-D pop-up sculptures with lights embedded in them. Katrina had never made a paper circuit before and had little familiarity with circuitry previous to this activity. She decided to create a "spooky" story of three children searching for "something" in the forest that, hidden behind a black flap of paper, happens to be a Halloween pumpkin with glowing red eyes. Driven by her personal interest in this story, Katrina drew out the scene on a green piece of paper and poked two tiny holes where she wanted red LEDs to shine through. Then, Lianna sat down with her and showed her how a parallel circuit worked, using a model. Lianna explained that LEDs formed a "bridge" between two strips of copper tape. Then Lianna suggested "we can even sketch it out if it's helpful. Sometimes I'll sketch my pathways first." Following this suggestion, Katrina took a second piece of paper for building her circuit (which she eventually taped to the back of her drawing so that only the LEDs would be visible through the pumpkin eyeholes, with the circuit hidden from view), and she began drawing her pathways from the battery to her LEDs. But she hesitated when trying to figure out where the LEDs should go. Noticing her hesitation, Lianna said encouragingly, "[it's] almost like connecting the dots" and she used her finger to point to how the copper tape could extend and touch both LEDs. Katrina took this metaphor and continued drawing out the circuit herself.

After placing copper tape on her circuit sketch, Katrina tried attaching red LEDs with scotch tape. She found that while the first one began to glow, the second one was not working. She wasn't sure why and so Lianna asked her if she had ever used a multimeter tool before. Katrina had never used this tool before so Lianna explained, "the way these things work is that they can tell us a lot of interesting stuff about circuits, but for paper circuits the most useful thing is they tell us if the electricity is going or if it's stuck. So when we touch these together: hear that annoying beep?" Katrina nodded her head and Lianna explained, "that let's us know the electricity is going." Katrina and Lianna proceeded to test Katrina's circuit together, each taking a different test lead.

After testing the circuit, they found that the flow of electricity was stopping at joints where two different pieces of copper tape were connected. Lianna suggested that one fix for this problem would be soldering those joints so that electricity could continue flowing along the copper tape. This resulted in another first for Katrina: she had never soldered before. So Lianna sat down with Katrina at a soldering station. Lianna taught her various safety measures (wearing goggles, being cautious about the hot tip of the iron, etc.) and then demonstrated, on a part of the circuit that did not need soldering, how to heat up the copper with the iron and touch the solder to the heated copper by the iron so that it could also heat up and flow. Then Lianna put down all the tools and materials explaining that Katrina would be doing the same thing at the break in her copper tape. Katrina proceeded through the process of soldering while Lianna talked her through each step without ever taking hold of the materials herself.

Finally, Katrina taped her circuit to the back of her drawing so the red LEDs could show through. Katrina looked at her project in its completion and stepped back in surprise, smiling. She was visibly pleased with the result and Lianna laughed with her while saying encouragingly, "it's definitely got the spooky thing going!" Then Lianna asked her, "was there anything especially tricky about building it?" Katrina replied, "what was tricky was probably having to figure out why and how they [the LEDs]... well how to fix the bridge [in the circuit] right here because it wasn't working for the second LED." Then Lianna asked, "do you have a favorite part of your circuit or your card?" Katrina replied, "it'll have to be soldering." Lianna noted, "well I think you'll have more chances to keep soldering!" and Katrina smiled.
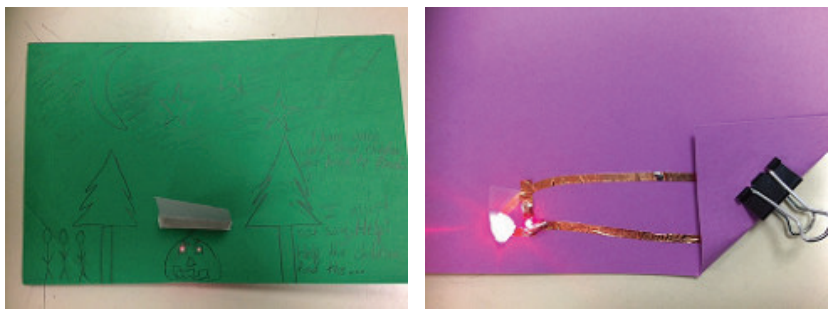

Figure 1. Katrina's circuit and spooky pumpkin.

In this first paper circuit project, Lianna didn't make assumptions about Katrina's knowledge. While asking probing questions to assess her understanding, she tried to connect to the knowledge 
that Katrina already had (about bridges or connect-the-dots), and she allowed Katrina's interest and goals to drive the direction of the project. With these pedagogical supports, Katrina demonstrated persistence through challenging moments when LEDs failed to light, working through problems while developing new skills. Driven by her personalization of the project, Katrina was able to experience foundational concepts in circuitry and electricity.

As part of the collaboration between Lighthouse, Exploratorium, and University of Washington, video footage from this experience was shown at the following professional development session. Educators from Lighthouse noticed key moments of teaching that were applicable to their own practice, and also gave feedback on how Katrina's enthusiasm and affect around showcasing her project was unusual given her usually shy nature. This insight also helped Lianna to support Katrina's future interactions with circuitry, particularly around giving her scaffolding and support to voice her thoughts and ideas. This professional development forum allowed for educators with different areas of expertise to share their knowledge in a way that led to immediate changes in Lianna's pedagogical practice.

\subsubsection{Katrina's Second Paper Circuit}

The following week, Katrina decided to make another paper circuit, but one that included a paper switch. (Her previous project had lit up by using a binder clip to attach copper strip and battery.) We had several examples of different kinds of paper switches available in the room to inspire ideas and serve as models. Katrina chose to try making the one shown below:

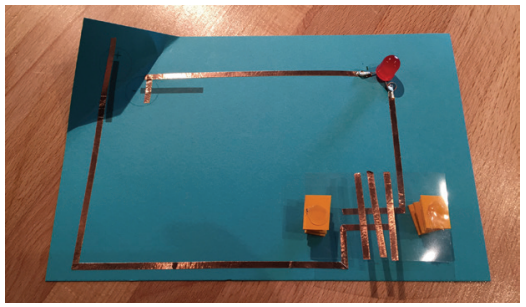

Figure 2. Example switch with a press button in the bottom right-hand corner.

After observing carefully to see how the switch worked, Katrina created a drawing of a little camera. She poked a hole where the flash was located on her camera and decided a white LED should glow through that hole when pressing the switch. Unlike her previous project where the circuit and drawing were on separate pieces of paper, Katrina decided to create the circuit directly on the back of her camera drawing. Using the skills she had learned the previous week and, without Lianna's assistance, she drew out her circuit and then laid down copper tape.

But now Katrina faced a new challenge: she wanted the front of the LED to shine through the hole, which would require soldering the LED to the copper tape while flipped upside down. Lianna came over and, hearing about Katrina's challenge, wondered whether it would be possible to solder the LED directly to the copper tape before laying it on her paper circuit. Lianna noted, "I've never done this before!" as they tried this new method and Katrina-using the soldering skills she learned the previous week-successfully soldered the LED to the copper tape. She tested it with a battery and the LED lit up.

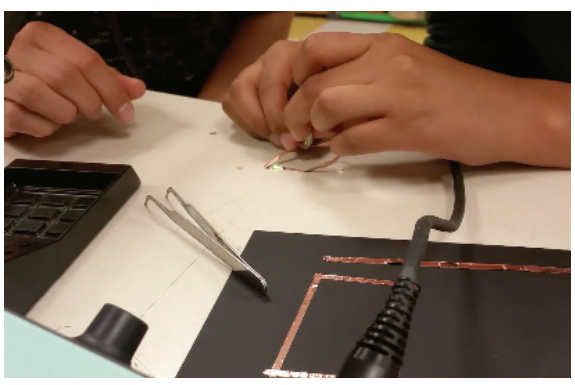

Figure 3. Katrina successfully solders an LED directly to copper tape.

However, after laying this LED down on the circuit, Katrina and Lianna tested the switch by pressing some copper tape across the disconnected copper pathways to see if connecting them would light up the LED. The LED wouldn't light. Again, using the multimeter tool she had learned about last week, Katrina tested her circuit and found that all the joints were well connected and electricity was moving through smoothly. Neither Lianna nor Katrina could figure out why the switch wasn't working, and so they took a snack break and Katrina sat and reflected on what it could be. Eventually, they returned to Katrina's project and, this time, they used a thicker metal wire rather than the single piece of copper tape as the switch to connect the copper pathways. This time the LED lit up! The two of them realized that the single piece of copper tape was not conductive enough to complete the circuit, whereas the metal wire was thicker and more substantive for connecting the copper pathways. Thus, Katrina made sure to add several pieces of copper tape across her switch to ensure conductivity across the circuit.

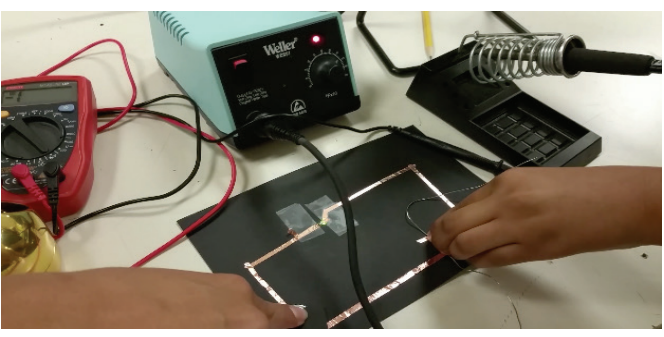

Figure 4. Testing the switch with a metal wire.

Before testing the final project, Katrina noted that she was "scared" to test it. But then she pressed down on her newly created switch and the camera lit up.
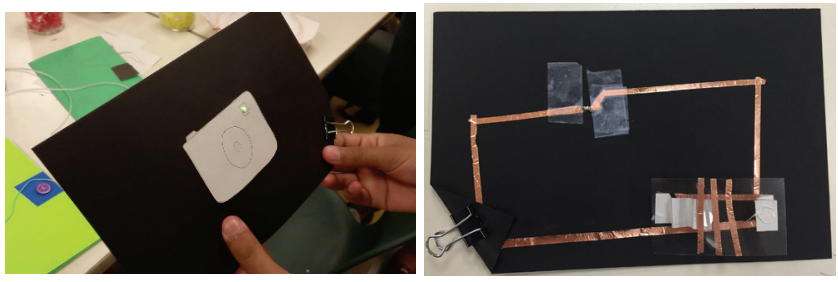

Figure 5. Katrina's switch and circuit work!

After creating this second paper circuit, Katrina wrote in her journal: "Today I made a camera flashing paper circuit. My favorite part about making this paper circuit was going through the process and learning from my mistakes." Katrina's reflection demonstrated important learning dispositions toward a sense of pride in working through challenges. Katrina's understanding about circuitry was reinforced through this experience of creating 
the circuit, testing the circuit, soldering to make the circuit stronger, and testing the switch. Yet Katrina not only reinforced what she learned the previous week. She also complexified her thinking about circuitry by building in a switch and experimenting with new ways of soldering LEDs into the circuit.

In the interactions between Katrina and Lianna we, again, saw how Lianna supported self-directed learning as an assistant to Katrina's vision and needs rather than the driver of Katrina's project. Lianna emphasized how she had never tried soldering directly to copper tape before adding it to a circuit, and became a student of the experience just as much as Katrina had been. Katrina was able to do things "her own way" and develop a project she could be proud of.

\subsubsection{Katrina's Tiny Theater - Building on Paper Circuits}

The final project of the semester involved creating a "Tiny Theater" that was a small story or series of scenes one could tell through a diorama in an enclosed shoebox with peepholes (a description of the activity is available here: http://tinkering.exploratorium.edu/2016/07/04/tiny-theaterslighthouse-asp).

Katrina had just attended the Goldman Environmental Prize ceremony in San Francisco with a school teacher the previous week and decided to create three scenes commemorating the life of Honduran environmental activist Berta Cácares who won an award last year but was "killed this year because she was fighting for someone's rights." As Katrina shared this story, we read online how Cácares kept various corporations from building a large dam that would destroy the indigenous landscape and lives.

Katrina's project continued to build on the previous weeks' learning about circuitry, switches, soldering, and multimeter circuit testing. This time she decided she wanted to include three switches that controlled three separate LEDs. Similar to previous projects, Katrina had to overcome challenges with weak electricity flow at copper tape circuit joints and where copper tape met LEDs. Yet unlike previous weeks, she immediately understood what aspects of her circuit to test and potential solutions for blocked electricity: She used her multimeter tool skills to test the circuit, and used this information to then decide where to add solder to her circuit.

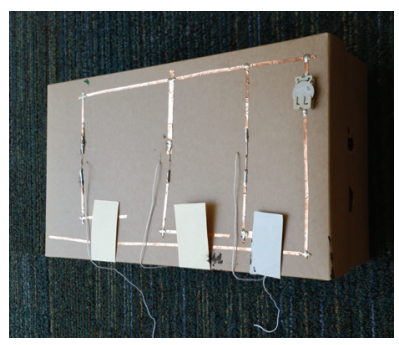

Figure 6. Katrina's three switches and Tiny Theater circuit.

The inside of her box showed three separate scenes, each lit up by a different LED/switch. The first scene showed the logo and sign for the Goldman Environmental Prize. The second scene showed a photo of Cácares receiving her prize the previous year. And the third scene showed a piece of paper commemorating the life of Cácares. Each scene was connected to a string that wove through the top of the box. The viewer was supposed to press on the light switch, then pull each string up to see the scene move into place.

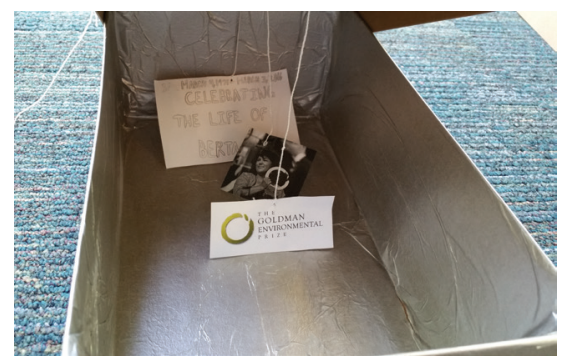

Figure 7. Three scenes of Katrina's Tiny Theater.

As in previous moments, Katrina was able to bring in not only her personal interests, but also her lived experiences from the school day into her project at hand. This was what became the inspiration for Katrina's project in ways that showed her own voice and perspective. At this point, Katrina had become so comfortable with checking electricity flow with a multimeter tool and with soldering that she needed almost no assistance from adults.

\subsubsection{Teaching as a Way of Learning}

On the last day of program, Katrina invited her friend to visit. She showed him her Tiny Theater, explaining that she was still working on soldering the final part of her circuit. He joined Katrina at the soldering station and she immediately provided him with safety tips, including the importance of wearing safety goggles and being cautious of the hot tip of the soldering iron. Then she asked if he wanted to learn to solder. He agreed he did, so she demonstrated how to solder one leg of a gumdrop LED while asking him to hold it down for her with tweezers. Then she asked if he wanted to try soldering the other leg while she held it down with the tweezers. He agreed and so they switched roles with Katrina holding down the LED leg while her friend tried soldering it.

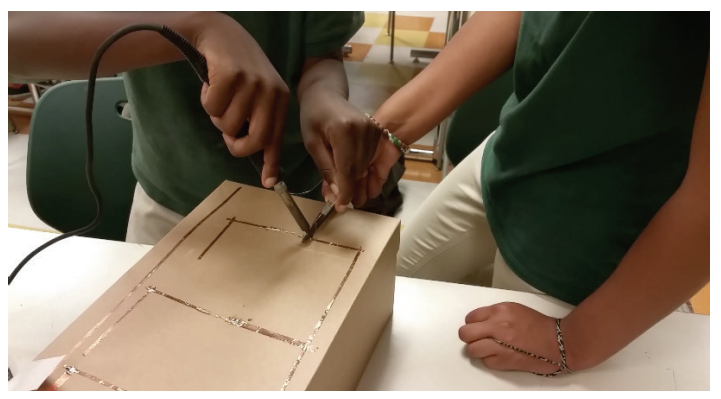

Figure 8. Katrina teaches her friend how to solder.

This moment was especially powerful, not only because it demonstrated how Katrina felt part of the community enough to welcome outsiders into the space, but also because she felt confident enough in her newly developed soldering skills to be able to teach a friend. Rather than relegate her friend to backseat while she controlled soldering her last LED, Katrina welcomed him to learn soldering by helping her with the final element of her project, even though this took longer than if she had just soldered everything herself.

Katrina's openness to teaching others reflected previous experiences she had in the community of learners. Katrina had previously been supported in her soldering by Ryan while a fellow student (Antero) looked over her shoulder. She had observed how adults assisted youth and youth assisted each other in the space, turning projects into more collaborative experiences rather than internally-focused endeavors. As such, she was able to emulate 
with her friend not only the teaching practices that Ryan and Lianna had demonstrated when working with her, but also continue this sense of collaboration with her friend in the room.

Katrina's desire to teach her friend how to solder was also a meaningful demonstration of her increased confidence considering her reflections on her first time soldering. While she worked on her Tiny Theater, Katrina shared that she remembered her first time soldering (the spooky pumpkin paper circuit) as "kinda fun" but also confessed that she had been "kinda scared...I was scared about messing up my project and hurting myself." Katrina clearly overcame those fears.

Katrina also developed a new interest in the concepts covered through these making activities. In her last journal entry, Katrina wrote: "I used to think that circuits weren't really interesting, but now I LOVE circuits. They are really fun and interesting to do and make."

Katrina's demonstration of soldering teaching became a meaningful source of professional development for Lianna as an educator in this space as well. Through a review of video and fieldnote data of Katrina's interactions with her friend, Lianna reflected on how it was powerful as an educator to see a student take agency in the space. This, in turn, supported Lianna in thinking about how she teaches youth to learn new skills and the subtle pedagogical practices they observe and take up in these moments that they may pass on when engaging with their peers. In this way, Katrina's act of teaching became a way not only for her friend to learn soldering, but for Lianna to learn about her own pedagogical practices as well.

\section{DISCUSSION AND CONCLUSION}

Katrina's case illustrates how an afterschool Tinkering program can be organized to support a range of learning dispositions, creative problem solving, and STEM understanding. Her projects and thinking became more complex over time as she built new skills, confidence, and interest through the program.

The important elements of building a new making program that supports developing important learning dispositions (e.g., engagement, persistence, etc.), capacities for creative problem solving, and STEM understanding for youth like Katrina-who did not necessarily identify as "makers" or reflect the white middle class male making image characterized on the Make magazine covers that Buechley previously critiqued [13]included careful equity-oriented pedagogical strategies (in program/curriculum design and teaching moves) and professional development focused on analyzing student learning toward building a creative making culture.

Our analyses of this new making program show how the organization of social learning contexts, pedagogy, educator professional development, and student learning are interrelated in important ways. Learning does not happen separate from teaching and shared activity in after school spaces. The results of our collaborative research did not reveal a student who was plopped into a makerspace and then left alone to blossom independently of others. Attention to the ways making programs attend to equity in order to support learning is important to share with the broader educational community [16].

Similarly, teaching does not involve implementing a static set of skills, but rather evolves and grows continuously with reflection and discussion with colleagues in a professional environment. Continuous reflection on teaching practice while looking at evidence of student learning was important for supporting growth among both students and teachers in this making space. This paper shows how professional development related to learning in these important ways.

Katrina's story also emphasizes why it is important for student voice and personal choice to drive creative projects while educators continue to engage with youth's learning processes [28]. Offering space and pedagogical support for students to choose the direction of their projects is especially important for youth of color whose perspectives, interests, and experiences are often treated as unrelated to traditional "science education" that values white and middle-class practices and epistemologies over the scientific ways of knowing and doing science experienced in "nondominant" communities [29].

Now the task at hand is to connect such student-driven learning across in-school and after school experiences.

\section{ACKNOWLEDGMENTS}

We would like to thank the students, educators, staff, and parents of Lighthouse Community Charter School who welcomed us into their family earlier this year. Specifically, we would like to thank the after school program students Sarah Chung, the Lighthouse afterschool Making co-teacher, Aaron Vanderwerff, director of the Lighthouse creativity lab and co-leader of the larger study. We would also like to thank our partners in this work including Mike Petrich and Karen Wilkinson, directors of the Exploratorium Tinkering Studio. Thanks as well to Lighthouse teachers-Asatu Hall, Joette Harris, Laila Jenkins-Perez, Juan Perez, Jessica Schipp, and Steven Stokes - for their wisdom and collaboration; and our Exploratorium Tinkering colleagues Luigi Anzivino, Nicole Bulalacao, Nicole Catrett, Michelle Choi, Ryan Jenkins, Sebastian Martin, and Ryoko Matsumoto.

This work was made possible through support from the Overdeck Foundation and the National Science Foundation (DUE1238253/DRL-1626365).

\section{REFERENCES}

[1] Bevan, B., Ryoo, J.J., \& Shea, M. (in press). Afterschool Matters.

[2] Ryoo, J.J., Bulalacao, N., Kekelis, L., McLeod, E., Henriquez, B. (2015, September). Tinkering with "failure": Equity, learning, and the iterative design process. Paper presented at FabLearn, Stanford, CA.

[3] Bevan, B. (in review). The promise and promises of Making.

[4] Peppler, K. A., Halverson, E. R., \& Kafai, Y. B. (Eds.). (2016). Makeology: Makerspaces as Learning Environments (Vol. 1). New York: Routledge.

[5] Vossoughi, S., \& Bevan, B. (2014). Making and tinkering: A review of the literature. Retrieved from

http://sites.nationalacademies.org/cs/groups/dbassesite/docu ments/webpage/dbasse 089888.pdf.

[6] Martinez, S. L., \& Stager, G. (2013). Invent to learn: Making, tinkering, and engineering in the classroom. Torrance: Constructing Modern Knowledge Press.

[7] Sheridan, K. M., Halverson, E. R., Brahms, L., Litts, B. K., Jacobs-Priebe, L., \& Owens, T., (2014). Learning in the making: A comparative case study of three makerspaces. Harvard Educational Review, 84(4), 505-531.

[8] Buchholz, B., Shively, K., Peppler, K., \& Wohlwend, K. (2014). Hands on, hands off: Gendered access in crafting and 
electronics practices. Mind, Culture, and Activity, 21(4), 278297.

[9] Blikstein, P. (2013). Digital fabrication and 'making' in education: The democratization of invention. In J. WalterHerrmann \& C. Büching (Eds.), FabLabs: Of Machines, Makers and Inventors. Bielefeld, Germany: Transcript Publishers, pp. 1-21.

[10] Resnick, M., and Silverman, B. (2005). Some reflections on designing construction kits for kids. Proceedings of Interaction Design and Children Conference, Boulder, CO.

[11] Dixon, C., \& Martin, L. (2014). Make to relate: Narratives of, and as, community practice. Paper presented at the International Conference of the Learning Sciences, Boulder, CO.

[12] Fields, D. A. \& King, W. L. (2014). "So, I think I'm a programmer now." Developing connected learning for adults in a university craft technologies course. In Polman, J. L., Kyza, E. A., O'Neill, D. K., Tabak, I., Penuel, W. R., Jurow, A. S., . . \& \& D'Amico, L. (Eds.). (2014). Learning and Becoming in Practice: The International Conference of the Learning Sciences (ICLS) 2014, Volume 1. Boulder, CO: International Society of the Learning Sciences, pp. 927-936.

[13] Buechley, L. (2013, October). Thinking about making. Keynote speech presented at FabLearn Conference, Stanford University, Stanford, CA.

[14] Chachra, D. (2015, January 23). Why I am not a maker. The Atlantic. Retrieved from

http://www .theatlantic.com/technology/archive/2015/01/why -i-am-not-a-maker/384767/.

[15] Gutiérrez, K.D. \& Jaramillo, N.E> (2006). Looking for educational equity: The consequences of relying on Brown. Yearbook of the National Society for the Study of Education, 105(2), 173-189.

[16] Vossoughi, S., Hooper, P.K., Escudé, M. (2016). Making through the lens of culture and power: Toward transformative visions for educational equity. Harvard Educational Review, 86(2), 206-232.

[17] Blikstein, P. \& Worsley, M. (2016). Children are not hackers: Building a culture of powerful ideas, deep learning, and equity in the Maker Movement. In K. Peppler, E. Halverson, \& Y.B. Kafai (Eds.), Makeology: Makerspaces as learning environments (Volume 1) (pp. 64-79). New York: NY: Routledge.
[18] Wilkinson, K. \& Petrich, M. (2015). The Art of Tinkering. San Francisco: WeldonOwen and the Exploratorium.

[19] Petrich, M., Wilkinson, K., \& Bevan, B. (2013). It looks like fun, but are they learning? In M. Honey \& D. Kanter, (Eds.), Design, make, play: Growing the next generation of STEM innovators (pp. 50-70). New York: Routledge.

[20] Vossoughi, S., Escudé, M., Kong, F., \& Hooper, P. (2013). Tinkering, learning \& equity in the after-school setting. Paper presented at FabLearn, Stanford, CA. Retrieved from http://fablearn.stanford.edu/2013/papers/.

[21] Resnick, M. \& Rosenbaum, E. (2013). Designing for tinkerability. In M. Honey \& D. Kanter (Eds.), Design, make, play: Growing the next generation of STEM innovators (pp. 163-181). New York: Routledge.

[22] Papert, S., \& Harel, I. (1991). Constructionism. New York: Ablex Publishing Corporation.

[23] Herrenkohl, L. R., \& Mertl, V. (2010). How students come to be, know, and do: A case for a broad view of learning. New York: Cambridge University Press.

[24] National Research Council. (2015). Identifying and supporting productive STEM programs in out-of-school settings. Washington, DC: National Academy of Science

[25] Erickson, F. (1998). Qualitative research methods for science education. In B.J. Fraser \& K.G. Tobin (Eds.), International handbook of science education (pp. 1155-1173). Dordrecht, The Netherlands: Kluwer Academic Publishers.

[26] Ryoo, J.J. \& Shea, M.V. (2015). Value Mapping: An activity for surfacing power dynamics and diverse perspectives in research-practice collaborations. San Francisco: Research+Practice Collaboratory. http://researchandpractice.org/resource/value-mapping/

[27] Tinkering Studio. (2015). About the Tinkering Studio: Our philosophy. Retrieved from http://tinkering.exploratorium.edu/about.

[28] Calabrese Barton, A., Tan E. \& Greenberg. D. (Forthcoming). The Makerspace movement: Sites of Possibilities for Equitable Opportunities to Engage STEM among Underrepresented Youth. Teachers College Record.

[29] Medin, D.L., \& Bang, M. (2014). Who's asking? Native science, western science, and science education. Cambridge, MA: Massacusetts Institute of Technology Press. 